\title{
Electron irradiation of carbon dioxide-carbon disulphide ice analog and its implication on the identification of carbon disulphide on Moon
}

\author{
B SIVARAMAN* \\ Atomic, Molecular and Optical Physics Division, Physical Research Laboratory, Ahmedabad 380 009, India \\ e-mail: bhala@prl.res.in
}

MS received 25 September 2014; revised 19 August 2015; accepted 7 September 2015

\begin{abstract}
Carbon dioxide $\left(\mathrm{CO}_{2}\right)$ and carbon disulphide $\left(\mathrm{CS}_{2}\right)$ molecular ice mixture was prepared under low temperature $(85 \mathrm{~K})$ astrochemical conditions. The icy mixture irradiated with keV electrons simulates the irradiation environment experienced by icy satellites and Interstellar Icy Mantles (IIM). Upon electron irradiation the chemical composition was found to have altered and the new products from irradiation were found to be carbonyl sulphide $(\mathrm{OCS})$, sulphur dioxide $\left(\mathrm{SO}_{2}\right)$, ozone $\left(\mathrm{O}_{3}\right)$, carbon trioxide $\left(\mathrm{CO}_{3}\right)$, sulphur trioxide $\left(\mathrm{SO}_{3}\right)$, carbon subsulphide $\left(\mathrm{C}_{3} \mathrm{~S}_{2}\right)$ and carbon monoxide $(\mathrm{CO})$. Results obtained confirm the presence of $\mathrm{CS}_{2}$ molecules in lunar south-pole probed by the Moon Impact Probe (MIP).
\end{abstract}

Keywords. Interstellar medium; interstellar icy mantles; icy satellites; radiation processing; carbon dioxide; carbon disulphide.

\section{Introduction}

Icy satellites and Interstellar Icy Mantles (IIM) are known to synthesize and harbour variety of molecules ranging from diatomic to complex molecules that take part in chemical reactions induced by energetic particles. The first identification of molecules, such as $\mathrm{CO}$, $\mathrm{CS}, \mathrm{OCS}, \mathrm{SO}$ and $\mathrm{SO}_{2}$ containing $\mathrm{C}-\mathrm{O}, \mathrm{S}-\mathrm{O}$ and $\mathrm{C}-\mathrm{S}$ bond in the InterStellar Medium (ISM) was made within a decade after 1969, when Apollo-11 landed on the Moon. Since then the formation of such simple molecules and the reactions where they take part in making the complex molecules were studied in laboratory simulations in both the gas and ice phase. ${ }^{1}$ Indeed, in such experimental simulations it is observed that several other carbon and sulphur bearing molecules, so far not reported to be present in the ISM, were also synthesized. For example, $\mathrm{CS}_{2}$ synthesis in laboratory simulations on carbon and sulphur containing molecular mixtures suggest the presence of $\mathrm{CS}_{2}$ in the IIM of ISM ${ }^{2}$ and this is clearly reflected in the identification of $\mathrm{CS}_{2}$ in comets. ${ }^{3,4}$

A few irradiation and implantation experiments were carried out to study the formation of sulphur bearing molecules at astrochemical conditions. Recent experiment carried out ${ }^{5}$ by implanting sulphur ions into $\mathrm{CO}$ and $\mathrm{CO}_{2}$ ices were observed to have altered the chemical composition where molecules containing $\mathrm{C}-\mathrm{S}$ bonds were synthesized, especially $\mathrm{CS}_{2}$ in the case of sulphur

*For correspondence implantation on $\mathrm{CO}_{2}$ ices. However, proton implantation on $\mathrm{SO}_{2}$ could not synthesize molecules containing $\mathrm{H}-\mathrm{S}$ bonds. ${ }^{6}$ Electron irradiation of $\mathrm{CS}_{2}$ and $\mathrm{O}_{2}$ ices carried out at $12 \mathrm{~K}^{7}$ had shown several products bearing $\mathrm{C}-\mathrm{O}$ and $\mathrm{S}-\mathrm{O}$ bonds. In another experiment ${ }^{3}$ synthesis of $\mathrm{C}-\mathrm{O}$ and $\mathrm{C}-\mathrm{S}$ bearing molecules were studied starting from $\mathrm{CO}$ with $\mathrm{SO}_{2} / \mathrm{H}_{2} \mathrm{~S}$ ices using proton irradiation.

In most of these experiments $\mathrm{CO}_{2}$ is one another molecule that is largely used as well as a product from synthesis in the study of sulphur bearing molecules. Indeed, in the IIM and icy satellite surfaces $\mathrm{CO}_{2}$ is known to be one of the most abundant $\mathrm{C}-\mathrm{O}$ bearing molecule. Therefore a mixture of $\mathrm{CO}_{2}$ and $\mathrm{CS}_{2}$ molecular ice may exist on the surface of icy satellites and in the IIM's, hence, it is imperative to understand the chemical synthesis in icy mixture containing $\mathrm{CO}_{2}$ and $\mathrm{CS}_{2}$. However, so far there is only limited data considering the $\mathrm{CO}_{2}-\mathrm{CS}_{2}$ system and the chemical synthesis induced by energetic processing. In this letter, the results from electron irradiation of $\mathrm{CO}_{2}-\mathrm{CS}_{2}$ ice studied at icy astrochemical conditions reproducing the surfaces of icy satellites and IIM, are reported for the first time, with implications.

\section{Experimental}

Electron irradiation experiment was carried out under astrochemical ice analog condition in the Low temperature astrochemistry experimental facility in Physical Research Laboratory (PRL). The Ultra High Vacuum 
(UHV) experimental chamber containing a liquid nitrogen cooled cold head simulates the icy astrochemical conditions. Details of the experimental chamber can be found in our very recent publication. ${ }^{8}$ Chemically inert and mid-Infrared (IR) transparent Zinc Selenide (ZnSe) window was used as the substrate, which upon cooling down to $85 \mathrm{~K}$ is an analogue of a dust surface for icy mantles.

$\mathrm{CS}_{2},>98 \%$ pure, along with the molecules of $\mathrm{CO}_{2}$, purity $99.9 \%$, were premixed before letting into the experimental chamber to form the icy layers of mixed $\mathrm{CS}_{2}-\mathrm{CO}_{2}$. After deposition at $85 \mathrm{~K}$, a spectrum in the $4000 \mathrm{~cm}^{-1}$ to $500 \mathrm{~cm}^{-1}$ region, was recorded before irradiation commenced. Electrons at $2 \mathrm{keV}$ and at $\sim 9$ $\mu$ A irradiated the sample for about 30 minutes with subsequent recording of IR spectra at regular intervals. Using the integral absorption coefficient (A) of the corresponding molecule and the infrared band intensity, the number of molecules of $\mathrm{CO}_{2}, \mathrm{CS}_{2}$ and other new products can be calculated as follows,

$$
N=\cos \left(45^{\circ}\right) \int \tau(v) d \nu / A
$$

where $\mathrm{N}$ represents the column density (molecules $\left.\mathrm{cm}^{-2}\right), \tau(v)$ the integrated band area. As the substrate is kept at an angle of $45^{\circ}$ to the IR beam, $\cos \left(45^{\circ}\right)$ is the correction factor for path length. As the molecules were deposited at $85 \mathrm{~K}$, the characteristic infrared band strengths $\mathrm{CO}_{2}$ and $\mathrm{CS}_{2}$ were used to calculate the number of molecules present in the ice phase rather than estimating the number of molecules in the gas phase prior to deposition.

\section{Results and Discussion}

IR spectra recorded after deposition showed several vibrational bands corresponding to $\mathrm{CO}_{2}$ and $\mathrm{CS}_{2}$ molecules. Fundamental, combination and overtone bands of $\mathrm{CO}_{2}$ were observed with peak positions at $3708.3 \mathrm{~cm}^{-1}, 3599.2 \mathrm{~cm}^{-1}, 2345.2 \mathrm{~cm}^{-1}, 660.1 \mathrm{~cm}^{-1}$, $655.3 \mathrm{~cm}^{-1}$ and $638.8 \mathrm{~cm}^{-1}$ (figure 1(a)) and in good agreement with other experimental data reported. ${ }^{9}$ The morphology dependent characteristic vibrational bands $2 v_{2}$ and $v_{1}$ of $\mathrm{CO}_{2}$ ice were found to be absent in the ice formed at $85 \mathrm{~K}^{9-11}$ However, the shoulder band at $2328 \mathrm{~cm}^{-1}$ was observed which arise due to $\mathrm{CO}_{2}$ dimer, $\left(\mathrm{CO}_{2}\right)_{2} \cdot{ }^{9}$ Vibrational features of $\mathrm{CS}_{2}$ were observed at $2146 \mathrm{~cm}^{-1}, 1511 \mathrm{~cm}^{-1}$ and $1460 \mathrm{~cm}^{-1}$ and in good agreement with other experimental data reported. ${ }^{7}$ In addition, to the bands corresponding to $\mathrm{CO}_{2}$ and $\mathrm{CS}_{2}$ a prominent band at with peak center at $1039 \mathrm{~cm}^{-1}$ was also observed where this could be from the $\mathrm{S}-\mathrm{O}$ vibration that can arise from the complex $\mathrm{CS}_{2}-\mathrm{CO}_{2}$.
On the onset of irradiation, new peaks were found in the recorded IR spectra whilst irradiating the sample. The peaks at $2142.4 \mathrm{~cm}^{-1}, 2060 \mathrm{~cm}^{-1}, 2044 \mathrm{~cm}^{-1}$ and $2035 \mathrm{~cm}^{-1}$ can be assigned to $\mathrm{CO},{ }^{12} \mathrm{C}_{3} \mathrm{~S}_{2},{ }^{7} \mathrm{CO}_{3}{ }^{13}$ and $\mathrm{OCS}^{14}$ molecules, respectively (figure $1(\mathrm{~b})$ ). In the finger print region, three new bands were observed with peak centers at $1330.2 \mathrm{~cm}^{-1}, 1148.4 \mathrm{~cm}^{-1}$ and the shoulder band at $1043.1 \mathrm{~cm}^{-1}$. The first two bands correspond to the characteristic vibration from $\mathrm{SO}_{2} \cdot{ }^{7}$ and the third corresponding to $\mathrm{O}_{3}$ molecule ${ }^{9}$ (figure $1(\mathrm{c})$ ). A set of weak bands were observed at $1396 \mathrm{~cm}^{-1}$ and 1386 $\mathrm{cm}^{-1}$ corresponding to $\mathrm{SO}_{3}$ molecule (figure 1(d)).

By analysing the IR bands observed before irradiation which clearly showed the absence of the morphology dependent characteristic band of $\mathrm{CO}_{2}$, suggesting a crystalline $\mathrm{CO}_{2}$ matrix to be present. Also the presence of the $2328 \mathrm{~cm}^{-1}$ band corresponding to the $\mathrm{CO}_{2}$ dimer ${ }^{9}$ shows the interaction between $\mathrm{CO}_{2}$ molecules. Using equation (1), the number of molecules of $\mathrm{CO}_{2}$ and $\mathrm{CS}_{2}$ present in the ice phase was calculated using their bands appearing at $3708.4 \mathrm{~cm}^{-1}$ and $1511 \mathrm{~cm}^{-1}$ along with their corresponding A values of $1.5 \times 10^{-18}(\mathrm{~cm}$ molecule $\left.{ }^{-1}\right)$ and $9.1 \times 10^{-17}\left(\mathrm{~cm} \mathrm{molecule}{ }^{-1}\right)$, respectively (table 1). About $\sim 2.2 \times 10^{17}$ molecules $\mathrm{cm}^{-2}$ of $\mathrm{CO}_{2}$ and $\sim 8 \times 10^{16}$ molecules $\mathrm{cm}^{-2}$ of $\mathrm{CS}_{2}$ (figure 2) were found to be present in the ice before irradiation suggesting the availability of twice as much as oxygen atoms for every sulphur atom present in the ice phase.

The set of new peaks in the spectra recorded at the time of and after irradiation indicates that new molecules have been formed from electron irradiation and are stable in the $\mathrm{CO}_{2}-\mathrm{CS}_{2}$ ice matrix. After assigning the new peaks to their characteristic vibrations corresponding to the specific molecule (table 1) and by applying equation (1), using the A values given in table 1 , the column densities of new molecules synthesized were obtained. At the end of irradiation, $\mathrm{SO}_{2}$ and $\mathrm{CO}$ were found to be the dominant products with column densities of $\sim 1.8 \times 10^{16}$ molecules $\mathrm{cm}^{-2}$ and $\sim 7 \times 10^{15}$ molecules $\mathrm{cm}^{-2}$, respectively (figure 2 ). Whereas column densities of $\mathrm{CO}_{3}$ and $\mathrm{O}_{3}$ were about $\sim 2 \times 10^{14}$ molecules $\mathrm{cm}^{-2}$ and $1 \times 10^{14}$ molecules $\mathrm{cm}^{-2}$, respectively. However, the lowest concentrations were found to be for $\mathrm{SO}_{3}$ and OCS with column densities of about $\sim 3 \times 10^{13}$ molecules $\mathrm{cm}^{-2}$ and $\sim 4 \times 10^{13}$ molecules $\mathrm{cm}^{-2}$, respectively (table 1). At the end of irradiation, number of molecules of $\mathrm{CO}_{2}$ and $\mathrm{CS}_{2}$ left out were $\sim 1.6 \times 10^{17}$ molecules $\mathrm{cm}^{-2}$ and $\sim 6 \times 10^{16}$ molecules $\mathrm{cm}^{-2}$, where nearly $5 \times$ $10^{16}$ molecules $\mathrm{cm}^{-2}$ of $\mathrm{CO}_{2}$ and $2 \times 10^{16}$ molecules $\mathrm{cm}^{-2}$ of $\mathrm{CS}_{2}$ were dissociated, respectively.

Necessary reactants for chemical reactions to synthesize these new products would have come from the dissociation of $\mathrm{CO}_{2}$ and $\mathrm{CS}_{2}$ molecules as given 


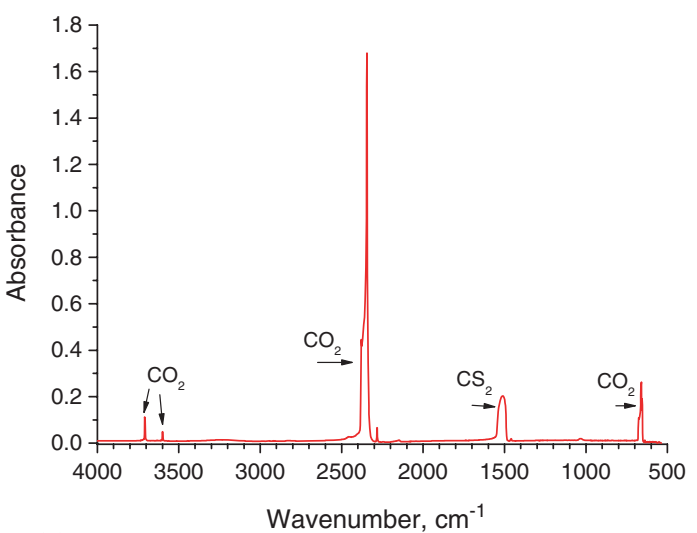

(a)

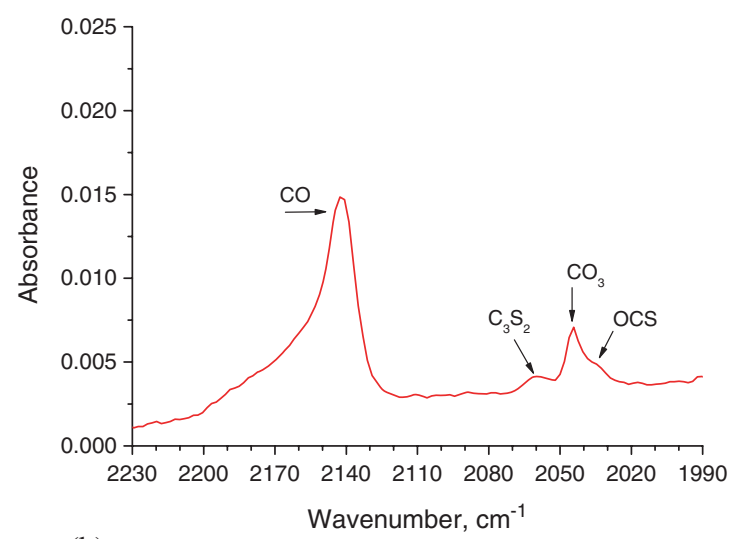

(b)

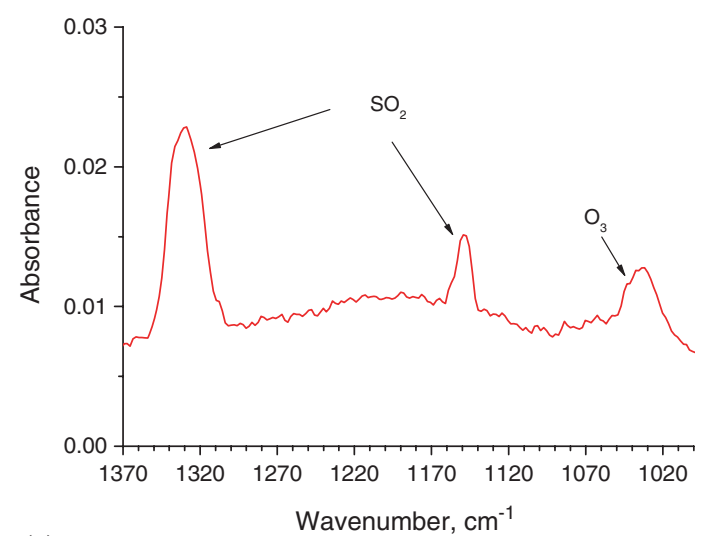

(c)

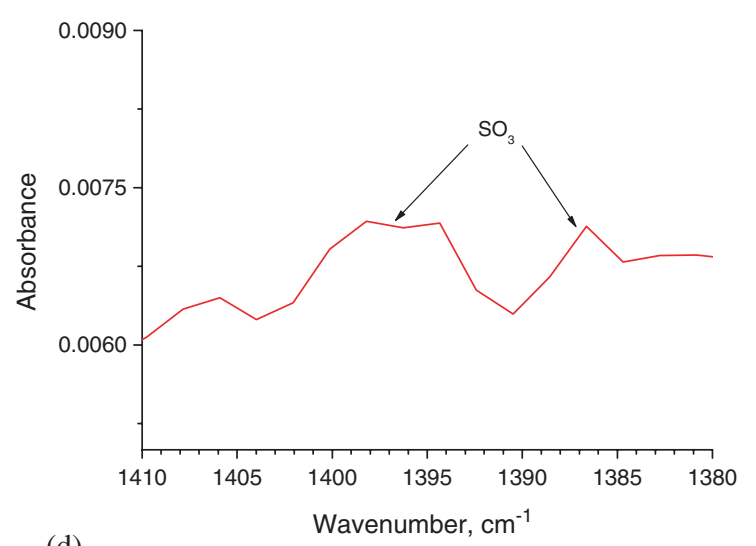

(d)

Figure 1. IR spectra recorded (a) after deposition of $\mathrm{CO}_{2}-\mathrm{CS}_{2}$ mixture on a $\mathrm{ZnSe}$ substrate at $85 \mathrm{~K}$; (b) after irradiation showing the characteristic vibrational bands of new molecules $\mathrm{CO}, \mathrm{CO}_{3}, \mathrm{C}_{3} \mathrm{~S}_{2}$ and OCS; (c) $\mathrm{SO}_{2}, \mathrm{O}_{3}$; and (d) $\mathrm{SO}_{3}$. Thickness of the film was not determined.

Table 1. IR signatures, column densities of the reactants $\mathrm{CO}_{2}$ and $\mathrm{CS}_{2}$ before/after $2 \mathrm{keV}$ electron irradiation and of the products observed.

\begin{tabular}{lcrcc}
\hline & $\begin{array}{c}\text { Peak position } \\
\left(\mathrm{cm}^{-1}\right)\end{array}$ & $\mathrm{A}\left(\mathrm{cm} \mathrm{molecull^{-1 } )}\right.$ & \multicolumn{2}{c}{ Column density $\left(\right.$ molecules cm $\left.^{-2}\right)$} \\
\cline { 4 - 5 } Molecule & Before irradiation & After irradiation \\
\hline $\mathrm{CO}_{2}$ & 3707 & $1.5 \times 10^{-18(\mathrm{a})}$ & $2.2 \times 10^{17}$ & $1.64 \times 10^{17}$ \\
$\mathrm{CO}$ & 2142.4 & $1.1 \times 10^{-17(\mathrm{~b})}$ & & $7.14 \times 10^{15}$ \\
$\mathrm{OCS}$ & 2035 & $1.5 \times 10^{-16(\mathrm{c})}$ & & $3.77 \times 10^{13}$ \\
$\mathrm{CO}_{3}$ & 2044 & $8.9 \times 10^{-17(\mathrm{~d})}$ & & $1.88 \times 10^{14}$ \\
$\mathrm{CS}_{2}$ & 1511 & $9.1 \times 10^{-17(\mathrm{e})}$ & $8 \times 10^{16}$ & $6.26 \times 10^{16}$ \\
$\mathrm{SO}_{3}$ & 1386 & $3 \times 10^{-17(\mathrm{f})}$ & & $3.06 \times 10^{13}$ \\
$\mathrm{SO}_{2}$ & 1330 & $1.5 \times 10^{-17(\mathrm{~g})}$ & & $1.8 \times 10^{16}$ \\
$\mathrm{O}_{3}$ & 1043 & $1.4 \times 10^{-17(\mathrm{~h})}$ & & $1.11 \times 10^{14}$
\end{tabular}

References: (a) Gerakines et al. ${ }^{19}$, (b) Jiang et al. ${ }^{12}$, (c) Hudgins et al. ${ }^{14}$, (d) Bennett et $a l .{ }^{13}$, (e) Pugh and Rao ${ }^{20}$, (f) Majkowski et al. ${ }^{21}$, (g) Garozzo et al. ${ }^{22}$, (h) Smith et al. ${ }^{23}$.

in equations (2) and (3). However, further dissociation of $\mathrm{CO}$ and $\mathrm{CS}$ molecules cannot be neglected due to continued irradiation.

$$
\begin{gathered}
\mathrm{CO}_{2} \rightarrow \mathrm{CO}+\mathrm{O} \\
\mathrm{CS}_{2} \rightarrow \mathrm{CS}+\mathrm{S}
\end{gathered}
$$

The column density of $\mathrm{CO}$ molecules can be regarded as the number of $\mathrm{O}$ atoms that are released from $\mathrm{CO}_{2}$ dissociation (equation 2). However, the number of $\mathrm{S}$ atoms that could be available after irradiation cannot be calculated due to the absence of CS band in the recorded IR spectra. In such a case, by adding the number of $\mathrm{S}$ atoms found in the products $\mathrm{SO}_{2}, \mathrm{SO}_{3}$ and OCS can be 


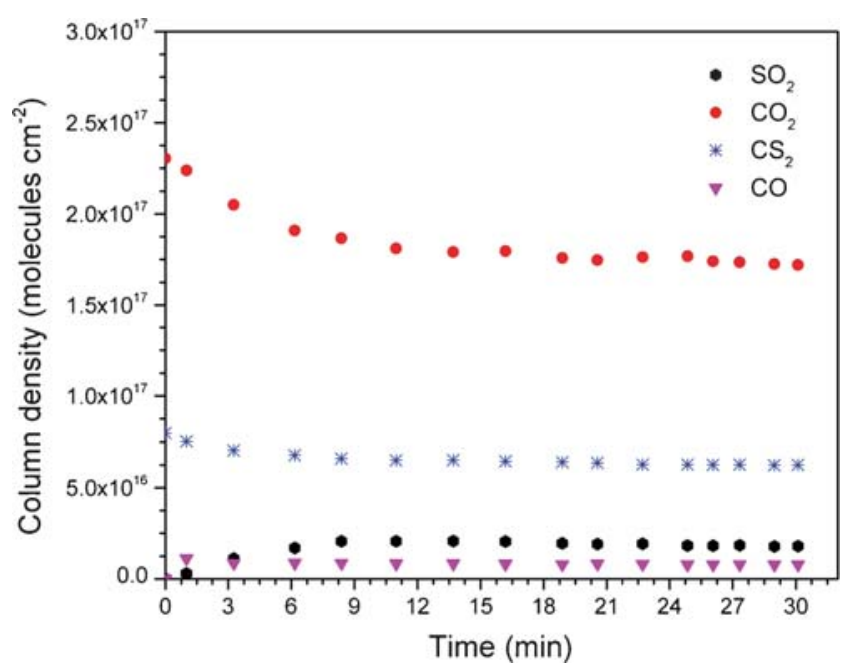

Figure 2. Temporal evolution of the new molecules synthesized, $\mathrm{SO}_{2}$ and $\mathrm{CO}$, and the number of $\mathrm{CO}_{2}$ and $\mathrm{CS}_{2}$ molecules dissociated by electron irradiation.

approximated to the number of $\mathrm{S}$ atoms released from $\mathrm{CS}_{2}$ and this gives an upper limit of $\sim 2 \times 10^{16}$ atoms $\mathrm{cm}^{-2}$. Considering equation (2) to be the dissociation pathway for $\mathrm{CO}_{2}$ generating $\mathrm{O}$ atoms, then an upper limit of $\mathrm{O}$ atoms generated would be $\sim 5 \times 10^{16}$ atoms $\mathrm{cm}^{-2}$.

It is quite surprising to note the column density of $\mathrm{SO}_{2}$ molecule which clearly shows the effective use of available $\mathrm{S}$ atoms, that are highly mobile at such higher temperatures, in synthesizing the molecule via reactions that can take place in two steps with the combination of an $\mathrm{S}$ and $\mathrm{O}$ atom in the first step followed by the addition of another $\mathrm{O}$ atom, or via a reaction of $\mathrm{S}$ atom with a molecule of oxygen, as given in the equations (4) and (5). Further reaction of the synthesized $\mathrm{SO}_{2}$ molecule was found to form $\mathrm{SO}_{3}$ in lesser concentrations. The formation pathway should be from the reaction (given in equation 6) of an $\mathrm{O}$ atom with $\mathrm{SO}_{2}$ molecule synthesized via reaction given in equation (4) or (5).

$$
\begin{aligned}
& \mathrm{S}+\mathrm{O} \rightarrow \mathrm{SO}^{(+\mathrm{O})} \rightarrow \mathrm{SO}_{2} \\
& \mathrm{~S}+\mathrm{O}_{2} \rightarrow \mathrm{SO}_{2} \\
& \mathrm{SO}_{2}+\mathrm{O} \rightarrow \mathrm{SO}_{3}
\end{aligned}
$$

As the number of oxygen atoms that are available for reaction is larger than the given amount of $\mathrm{S}$ atoms, other reactions involving $\mathrm{O}$ atoms do take place synthesizing $\mathrm{CO}_{3}, \mathrm{O}_{3}$ and $\mathrm{OCS}$. Synthesizing $\mathrm{CO}_{3}$ could be via $\mathrm{O}$ atom addition to $\mathrm{CO}_{2}$, as given in equation (7), whereas for making $\mathrm{O}_{3}, \mathrm{O}$ atoms have to undergo a series of two-step reaction in synthesizing $\mathrm{O}_{2}$ first and an addition of $\mathrm{O}$ atom to make $\mathrm{O}_{3}$, as given in equation (8). However, synthesizing OCS could occur via an addition of $\mathrm{O}$ to $\mathrm{CS}$ or $\mathrm{S}$ to $\mathrm{CO}$ (equation 10) with a third possibility of $\mathrm{C}, \mathrm{S}, \mathrm{O}$ atoms combining first to make either $\mathrm{CS}$ or $\mathrm{CO}$ first and then adding $\mathrm{O}$ or $\mathrm{S}$, respectively, to synthesize OCS. Though the absence of the CS infrared signature may look like CS could be consumed in making OCS, the number of molecules of OCS synthesized was only $\sim 4 \times 10^{13}$ molecules which suggest other dominant pathway synthesizing OCS, which can be explored by isotopically labelling the reactants $\mathrm{CO}_{2}$ and $\mathrm{CS}_{2}$. In the case of $\mathrm{C}_{3} \mathrm{~S}_{2}$, formation pathway via the decomposition (equation 10) of three molecules of $\mathrm{CS}_{2}$ upon electron irradiation yielding $\mathrm{C}_{3} \mathrm{~S}_{2}$, analogous to $\mathrm{C}_{3} \mathrm{~S}_{2}$ synthesis in discharge experiments, ${ }^{15}$ is proposed. If this pathway is followed then this could explain the absence of CS band and additional source for the S atoms for reactions.

$$
\begin{gathered}
\mathrm{CO}_{2}+\mathrm{O} \rightarrow \mathrm{CO}_{3} \\
\mathrm{O}+\mathrm{O} \rightarrow \mathrm{O}_{2}^{(+\mathrm{O})} \rightarrow \mathrm{O}_{3} \\
\mathrm{CS}+\mathrm{O} \text { (or) } \mathrm{S}+\mathrm{CO} \rightarrow \mathrm{OCS} \\
3 \mathrm{CS}_{2}^{(-4 \mathrm{~S})} \rightarrow \mathrm{C}_{3} \mathrm{~S}_{2}
\end{gathered}
$$

\subsection{Implication}

Results obtained show efficient synthesis of $\mathrm{SO}_{2}$ from $\mathrm{CO}_{2}-\mathrm{CS}_{2}$ ices, suggesting that origin of $\mathrm{SO}_{2}$ could be from such an icy mixture processed by energetic particles. This implies that $\mathrm{SO}_{2}$ on Lunar south pole, could have been synthesized by the mixture of $\mathrm{CO}_{2}-\mathrm{CS}_{2}$ ices, where $\mathrm{SO}_{2}$ and $\mathrm{CO}_{2}$ molecule in abundances of $3.19 \%$ and $2.17 \%$, respectively, relative to $\mathrm{H}_{2} \mathrm{O}$ molecule was confirmed by LCROSS. ${ }^{16}$ Though chemical reactions studied experimentally suggest the presence of $\mathrm{CS}_{2}$, so far it was not reported. Indeed, the evidence for the presence of $\mathrm{CS}_{2}$ was found in the data sent by the Chandra's Altitudinal Composition Explorer (CHACE) instrument on $\mathrm{MIP}^{17}$ where mass of 76 amu corresponding to $\mathrm{CS}_{2}$ was found at $\sim 9 \times 10^{-13}$ Torr (partial pressure) in the exosphere at the Lunar south pole (figure 3). In fact, the ChACE instrument on MIP was used to confirm minor chemical constituents such as $\mathrm{O}_{3},{ }^{18}$ which is also a product observed in the present study. Owing to the larger abundances of $\mathrm{SO}_{2}$ molecules, there could be several other pathways synthesizing $\mathrm{SO}_{2}$ via other sulphur bearing molecules such as $\mathrm{H}_{2} \mathrm{~S}$, however, the reaction channels from $\mathrm{S}$ atoms originating from the 


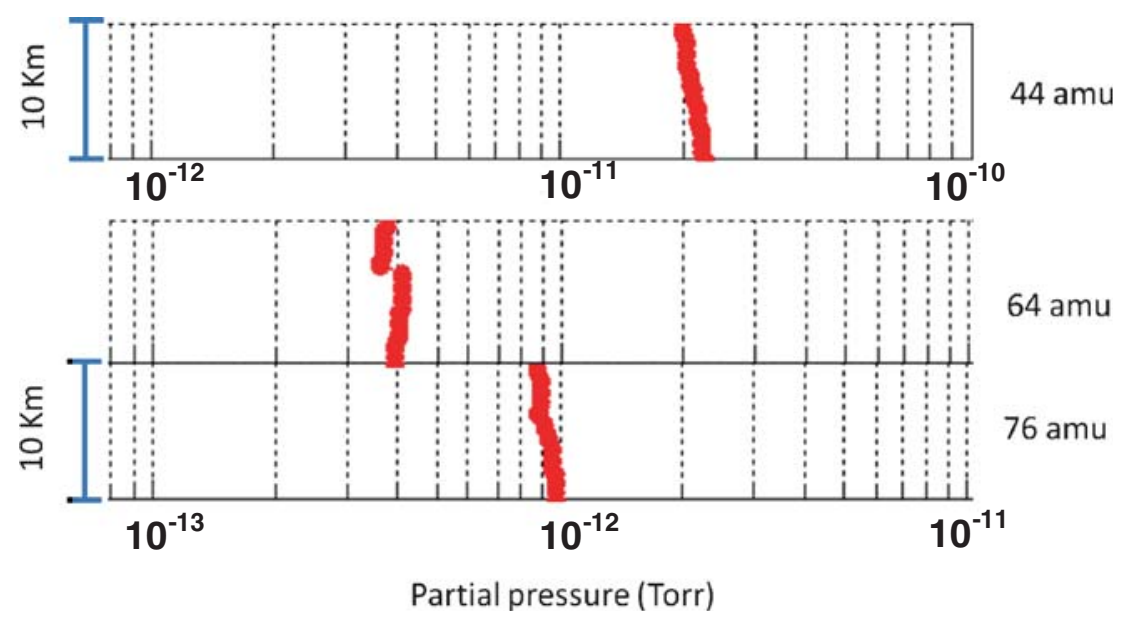

Figure 3. Partial pressure (in Torr) for mass of $76 \mathrm{amu}, 64 \mathrm{amu}$ and $44 \mathrm{amu}$ corresponding to $\mathrm{CS}_{2}, \mathrm{SO}_{2}$, and $\mathrm{CO}_{2}$, respectively, in the Lunar south pole observed by the CHACE on MIP. Data on $\mathrm{CO}_{2}$ and $\mathrm{SO}_{2}$ are adapted from Sivaraman et al. ${ }^{18}$

$\mathrm{CS}_{2}$ molecules, in the Lunar south pole, will also contribute to the chemical synthesis leading to $\mathrm{SO}_{2}$ and other sulphur bearing molecules.

\section{Conclusions}

$\mathrm{CO}_{2}-\mathrm{CS}_{2}$ ice kept at $85 \mathrm{~K}$ was irradiated by $2 \mathrm{keV}$ electrons, simulating the surface ices of icy satellites and the IIM. Molecular dissociation of $\mathrm{CO}_{2}$ and $\mathrm{CS}_{2}$ provided the necessary $\mathrm{O}$ and $\mathrm{S}$ atoms to take part in reactions synthesizing $\mathrm{SO}_{2}, \mathrm{CO}, \mathrm{SO}_{3}, \mathrm{O}_{3}, \mathrm{CO}_{3}$ and $\mathrm{OCS}$, whereas a direct dissociation of $\mathrm{CS}_{2}$ trimer molecules could be yielding $\mathrm{C}_{3} \mathrm{~S}_{2}$. Column density of molecules synthesized clearly showed the dominant product to be $\mathrm{SO}_{2}$ suggesting most of the $\mathrm{S}$ atoms to have been effectively undergone reaction with the much abundant $\mathrm{O}$ atoms in the ice matrix. A series of reactions involving $\mathrm{O}$ atoms, in synthesizing $\mathrm{O}_{3} / \mathrm{CO}_{3} / \mathrm{SO}_{3} / \mathrm{SO}_{2}$, revealed the different pathways undergone by the energetic $\mathrm{O}$ atoms; a limiting reactant in the formation of higher oxides of carbon and sulphur. The results obtained suggest that higher oxides of sulphur, up to $\mathrm{SO}_{3}$, can be synthesized even in chemically diverse system such as the $\mathrm{CO}_{2}-\mathrm{CS}_{2}$ used in this experiment. However, the dominant formation pathway in synthesizing OCS in the $\mathrm{CO}_{2}-\mathrm{CS}_{2}$ ice matrix could be deduced by isotopically labelling the reactant partners, which will be carried out in future experiments.

\section{Acknowledgements}

BS would like to acknowledge the support from members of the MOL-PH group. Thanks to Prof. Sridharan, for the data from CHACE on MIP, and Prof. Nigel
Mason, Dr. Raja Sekhar, Prof. K P Subramanian and Dr. Smitha Thambi for discussion during the preparation of this manuscript. Support from Jasleen Birdi, IITDelhi, during the course of this experiment is greatly acknowledged.

\section{References}

1. Abbas H 2014 Astrophys. Space Sci. 35153

2. Ferrante R H, Moore M H, Spiliotis M M and Hudson R L 2008 Astrophys. J. $\mathbf{6 8 4} 1210$

3. Garozzo M, Fulvio D, Kanuchova Z, Palumbo M E and Strazzulla G 2010 Astron. Astrophys. 509 A67

4. Jackson W M, Scodinu A, Xu D and Cochran A L 2004 Astrophys. J. Lett. 607 L139

5. Lv X Y, Boduch P, Ding J J, Domaracka A, Langlinay T, Palumbo M E, Rothard H and Strazzulla G 2014 MNRAS 438922

6. Strazzulla G 2011 Nucl. Instrum. Meth. B 269842

7. Maity S and Kaiser R I 2013 Astrophys. J. 773184

8. Sivaraman B, Mukherjee R, Subramanian K P and Banerjee S B 2014 Chem. Phys. Lett. 609167

9. Sivaraman B, Raja Sekhar B N, Fulvio D, Hunniford A, McCullough B, Palumbo M E and Mason N $2013 \mathrm{~J}$. Chem. Phys. 139074706

10. Falk M 1987 J. Chem. Phys. 86560

11. Gerakines P A and Hudson R L 2015 Astrophys. J. Lett. 808 L 40

12. Jiang G J, Person W B and Brown K G 1975 J. Chem. Phys. 621201

13. Bennett C J, Jamieson C, Mebel A M and Kaiser R I 2004 PCCP 6735

14. Hudgins D M, Sandford S A, Allamandola L J and Tielens A G G M 1993 Astrophys. J. Suppl. S 8698

15. Stadlbauer W and Kappe T 1999 Sulfur Reports 21423

16. Colaprete A, Schultz P, Heldmann J, Wooden D, Shirley M, Ennico K, Hermalyn B, Marshall W, Ricco A, Elphic R C, Goldstein D, Summy D, Bart G D, Asphaug E, Korycansky D, Landis D and Sollitt L 2010 Science 330 463 
17. Sridharan $\mathrm{R}$, Ahmed $\mathrm{S} \mathrm{M}$, Das $\mathrm{T} \mathrm{P}$, Sreelatha $\mathrm{P}$, Pradeepkumar P, Naik N and Supriya G 2010 Planet. Space Sci. $\mathbf{5 8} 947$

18. Sivaraman B, Nair B G, Raja Sekhar B N, Lo J I, Sridharan R, Cheng B M and Mason N J 2014 Chem. Phys. Lett. 60333

19. Gerakines P A, Schutte W A, Greenberg J M and van Dishoeck E F 1995 E F $A$ \& $A$ 810
20. Pugh L A and Rao K N 1976 In Molecular Spectroscopy: Modern research III (New York: Academic Press)

21. Majkowski R F, Blint R J and Hill J C 1978 Appl. Optics 17975

22. Garozzo M, Fulvio D, Gomis O, Palumbo M E and G Strazzulla G 2008 Planet. Space Sci. 561300

23. Smith M A H, Rinsland C P, Fridovich B and Rao K N 1985 In Molecular Spectroscopy: Modern Research III (New York: Academic Press) 